\title{
Prevalence of Chest Trauma at Tertiary Care Institute: A Cross Sectional Study
}

\author{
Jitesh Tolia ${ }^{\circledR}$, Arvind Bhatt ${ }^{2}$ \\ 1Professor, Department of Surgery, L. R. Shah Homoeopathy College, Rajkot, Gujarat, India, ${ }^{2}$ Principal, L. R. Shah Homoeopathy College, Rajkot, Gujarat, India.
}

\section{Abstract}

Background: Trauma is the leading cause of mortality and disability, especially during the productive age, and is the third most common cause of death. Present study carried out to assess the general spectrum of chest injury patients at tertiary care institute of Gujarat. Subjects and Methods: A total number of 500 patients were admitted with chest were included in the study. Details of all these patients were entered in the study from their records with specific reference to age, sex, mode of injury, severity of injury, number of ribs fractured, treatment employed and final outcome. Results: Out of a total of 500 patients, the maximum was in the age group of 20-29 years and the next common decade was the 4 th one. There were 380 male and 120 female patients. Blunt trauma was responsible for the injury in 405 patients and 95 patients sustained chest injury after penetrating trauma. Regarding treatment profile, no active treatment was required in 135 cases with either one or two rib fractures on x-rays without any haemopneumothorax. Intercostal drainage was required in 330 patients and thoracotomy was essential in 35 patients. Conclusion: Early recognition and management of associated injuries and complications is of paramount importance in reducing the morbidity and mortality. The majority of these patients can be managed by simple intervention i.e., intercostal drainage and only less than $10 \%$ require thoracotomy. For ICD, results of negative suction pleural drainage are better as compared to simple underwater seal drainage.

Keywords: Haemopneumothorax, Intercostal drainage, Thoracotomy, Trauma

Corresponding Author: Arvind Bhatt, Principal, L. R. Shah Homoeopathy College, Rajkot, Gujarat, India.

E-mail: ajbhatt@gardividyapith.ac.in

Received: 21 December 2019

Revised: 27 January 2020

Accepted: 1 February 2020

Published: 26 May 2020

\section{Introduction}

Trauma is the leading cause of mortality and disability, especially during the productive age, and is the third most common cause of death. ${ }^{[1]}$ Accidents which are unexpected and unplanned events are becoming the major epidemic of the present century. The number of accidental deaths in India is even higher than in the Western World. Thoracic trauma contributes heavily to these figures besides head injury, abdominal injury and orthopedic injuries. Approximately one quarter of civilian trauma deaths are caused by thoracic trauma and many of these deaths can be prevented by prompt diagnosis and correct management. ${ }^{[2]}$

Thoracic cage contains the most vital organs - heart, lungs and the great vessels and it has to give protection to the vital organs as well as preserve the unique function of expansion of lungs to ensure proper oxygenation of blood. Although, the ribs sternum and vertebral column which form this sturdy but pliable rib cage gives enough protection, there are certain weak points in this structure like the intercostal spaces, angles of ribs and costochondral junctions. Thoracic traumas might lead to severe consequences, even though less than $50 \%$ of them required a surgical revision. ${ }^{[3]}$ Thoracic traumas can be divided in blunt or penetrating, according to the presence of open wound in the chest.

In blunt traumas, rib fractures are common and they might be associated with haemothorax, pneumothorax or haemopneumothorax that are the most typical lesions that need to be faced by thoracic surgeons; moreover, lung injuries such as contusion or laceration can also be found.

On the other hand, penetrating trauma is mostly related to stubbing and gunshot and they usually present with lung or other thoracic organs lesions. Mortality related to penetrating chest traumas is significantly higher than blunt traumas, and more than $90 \%$ is not able to reach the hospital alive; nevertheless, mortality for patients with no cardiac involvement is less than $1 \% .{ }^{[4]}$

In spite of the high mortality rates, about $90 \%$ of the patients with life threatening thoracic injuries can be managed by a simple intervention like drainage of the pleural space by tube thoracostomy. ${ }^{[5]}$ Present study carried out to assess the general 
spectrum of chest injury patients at tertiary care institute of Gujarat.

\section{Subjects and Methods}

Particulars of all patients with chest trauma who required hospitalization in the last year were recorded and analyzed. A patient was labeled as a case of chest injury when he was having injury to the chest associated with fractured ribs with or without haemopneumothorax or injury to the chest with haemopneumothorax even without fractured ribs. A total number of 500 patients were admitted with chest were included in the study. Details of all these patients were entered in the study from their records with specific reference to age, sex, mode of injury, severity of injury, number of ribs fractured, treatmentemployed and final outcome.

\section{Statistical analysis}

The data were analyzed using SPSS version 15 (SPSS Inc., Chicago, Illinois, USA). For all tests, confidence level and level of significance were set at $95 \%$ and $5 \%$ respectively.

\section{Results}

Five hundred patients were admitted primarily because of chest injury. The rest of the patients were having head injury, abdominal injury or other injuries. Out of a total of 500 patients, the maximum was in the age group of 20-29 years and the next common decade was the $4^{\text {th }}$ one. So more than half of all the patients were in the $3^{\text {rd }}$ and $4^{\text {th }}$ decade of life and the incidence was low for very young and very old patients. There were 380 male and 120 female patients. Blunt trauma was responsible for the injury in 405 patients and 95 patients sustained chest injury after penetrating trauma. In blunt trauma, road-side accidents was the commonest cause, others being fall from height, assault, etc. [Table 1].

The right side was involved in 240 and the left side in 165 patients with blunt injury, while in penetrating injuries, the right side was affected in 35 and the left side in 60 cases. Single rib fracture was evident on x-ray in 70 patients, two fractured ribs were seen in 105 patients and in 255 patients there were multiple ribs fractured. In 65 patients, multiple rib fractures were also associated with flail chest. In 80 cases there was no evidence of fractured ribs on x-ray but still they developed either pneumothorax or haemopneumothorax. Regarding treatment profile, no active treatment was required in 135 cases with either one or two rib fractures on x-rays without any haemopneumothorax. Intercostal drainage was required in 330 patients and thoracotomy was essential in 35 patients [Table 2].

Ventilatory support to maintain $\mathrm{O} 2$ saturation was needed in 45 patients. Out of these 45 patients, ventilatory support was needed in 35 patients because of flail chest and in 10 patients after thoracotomy. Various indications of thoracotomy are shown in [Table 3].

In the majority of patients i.e., in 330 cases, tube thoracostomy was the main treatment employed. Initially, we were treating these cases by simple intercostal drainage and they required tube drainage for 2-9 days. And lately we have started applying negative suction to the drainage system requiring intercostals drainage for 2-6 days. If we analyze the final outcome of all the chest injury patients (500), 390 patients were discharged in satisfactory condition within 7-10 days, while hospital stay was prolonged in 60 patients because of some complications of ICD and 50 patients could not be saved despite adequate and aggressive treatment. Complications seen after ICD were residual haemothorax, recurrent pneumothorax and empyema. Out of 25 patients with empyema, 18 were treated by prolonged ICD and the remaining 7 developed chronic empyema with thickened pleura requiring thoracotomy with decortication.

\begin{tabular}{|c|c|c|c|}
\hline \multicolumn{2}{|c|}{ Blunt Trauma (405) } & \multicolumn{2}{|c|}{ Penetrating trauma (95) } \\
\hline $\begin{array}{l}\text { Road side } \\
\text { accidents }\end{array}$ & 301 & Stab & 84 \\
\hline $\begin{array}{l}\text { Fall from } \\
\text { height }\end{array}$ & 35 & & \\
\hline Assault & 55 & Gun shot & 11 \\
\hline $\begin{array}{l}\text { Animal } \\
\text { related } \\
\text { causes }\end{array}$ & 14 & & \\
\hline
\end{tabular}

\begin{tabular}{ll}
\hline Table 2: & Treatment profile of study participants \\
\hline Treatment Profile & No of patients (500) \\
No Active Treatment & 135 \\
Intercostal drainage & 330 \\
Thoracotomy & 35 \\
\hline
\end{tabular}

\begin{tabular}{ll}
\hline Table 3: Indications of thoracotomy among study participants \\
\hline Treatment Profile & No of patients \\
\hline Massive Bleeding & 16 \\
Ruptured Bronchus & 6 \\
Cardiac Tamponade & 3 \\
Diphragmatic hernia & 6 \\
Others & 4 \\
\hline
\end{tabular}




\section{Discussion}

Trauma is the leading cause of mortality and morbidity during the first four decades of life, and one of the commonest causes of death. Blunt or a penetrating injury can traumatize any one or multiple components of the thoracic cage or internal organs at a time. Overall prognosis of all the injuries will depend upon various factors like age of the patient, severity, time interval between trauma and treatment, severity of associated injuries etc.

More than half of the patients were in the $3^{\text {rd }}$ and $4^{\text {th }}$ decades of life and the incidence was low in very young and very old patients. The higher incidence in young age was due to the fact that this is the most active period of life. The higher percentage of younger age group patients in the present study is comparable to studies of Muckart and Locurto et al, ${ }^{[6,7]} \mathrm{M}$. Mohta et al, ${ }^{[8]}$ reported $49.55 \%$ patients in their study of 105 in the same age group (21-40 years). Massaga et al, ${ }^{[9]}$ had $43.75 \%$ patients from age group of 30 to 49 years. The highest incidence in this age group can be attributed to the active lifestyle with exposure to factors like use of automobiles, working with machinery, assaults and contact sports.

Males outnumbered females by a huge margin because of their greater exposure to outdoor activities like drivers, industrial workers and labourers etc. These findings were comparable to findings of other studies. Other studies have shown similar findings. Monafishha et $\mathrm{al}^{[10]}$ reported male incidence of 79.35 in the study of 150 cases. In the study by M. Mohta et al, ${ }^{[8]} 95$ out of 105 patients of chest trauma were males.

Motor vehicle accidents accounted for more than half of all the injuries. F. A. Massaga et al. reported that $72.3 \%$ cases were due to vehicular accidents. ${ }^{[9]}$ In a study of 1164 patients of chest trauma by Veysi et al, ${ }^{[11]} 57.01 \%$ cases were due to automobile accidents. Automobile accidents are major causes of polytrauma. Most of the victims suffer chest injuries when they are involved in polytrauma, rapid industrialization, higher rates of economic growth and better living standards have increased the use of high speed automobiles in our country. Our roads are not so good for such vehicles. Rules and regulations regarding safety are not followed stringently. Morbidity and mortality is going to increase in coming days which will be a serious medical and socioeconomical problem. Ibrahim et al, ${ }^{[12]}$ have reported incidence of $41 \%$ (365 out of 888) cases due to assault. Probably the study was conducted in a troubled area as no other study has similarly higher incidence.

Blunt trauma, mainly road-side accidents formed the most common cause of chest injury, followed by blunt assault, stab by knives and falls etc. Increased automobile traffic and ever increasing population together with intentional or unintentional ignorance of traffic rules account for the predominance of road-side accidents producing chest trauma.
These findings were in accordance with the studies of Helling and Mattox, in which road accidents constituted.

The right side of the chest was involved commonly after blunt injury while left side involvement was more common after penetrating injuries, which is consistent with assault by a right-handed assailant. Muckart et al. have observed a similar finding in which $61 \%$ of stab wounds occurred in the left pleural cavity. ${ }^{[6]}$ In our study, the majority of patients had fractures of more than two ribs. With single or two rib fractures the incidence of pneumothorax/haemothorax is not as high but there is increasing likelihood of this complication as the number of fractured ribs increases. ${ }^{[13]}$

Regarding treatment profile, intercostal drainage was required in 330 patients and thoracotomy was needed in 35 patients only. Although chest drain insertion is a quite common procedure, a correct training is required before being able to do it properly and safely. ${ }^{[14]}$ As a matter of fact; complication rates are strictly related to the experience of the operator. Earlier we were carrying out chest drainage by simple underwater seal drainage but recently we have started applying negative suction to the pleural drainage system. Time taken for full expansion of the lung and removal of the chest tube was 2-9 days in Group A and 2-6 days in Group B. So the chest tube was required for a lesser duration in Group B patients. In a study by Locurto, the chest tube was kept for an average 4.5 days with simple underwater seal drainage. ${ }^{[14]}$

Residual haemothorax was the commonest complication in our series, 25 of which were treated by simple aspiration while the remaining required repeat ICD. Drummond observed residual haemothorax in about $15 \%$ of patients with haemopneumothorax where simple ICD was done. ${ }^{[15]}$

Empyema was seen in 25 patients, 18 of which were treated by prolonged ICD and the remaining 7 developed chronic empyema with thickened pleura requiring thoracotomy and decortication later on. S. Dalal et al. ${ }^{[16]}$ reported that $90 \%$ of patients with thoracic injuries could be managed by tube thoracostomy. Many other studies have shown similar results. F.A.Massaga et al, ${ }^{[9]}$ reported $56.3 \%$ of cases had tube thoracostomy done in their study.

\section{Conclusion}

Outcome of a victim of chest trauma depends on various factors. Morbidity and mortality varies with age of the patient and force and location of trauma. Associated injuries increase the risk of complications in patients with chest trauma. Delay in diagnosis and treatment and respiratory complications increase the mortality. Early recognition and management of associated injuries and complications is of paramount importance in reducing the morbidity and mortality. The majority of these patients can be managed by 
simple intervention i.e., intercostal drainage and only less than $10 \%$ require thoracotomy. For ICD, results of negative suction pleural drainage are better as compared to simple underwater seal drainage.

\section{References}

1. Kamal VK, Agrawal D, Pandey RM. Epidemiology, clinical characteristics and outcomes of traumatic brain injury: Evidences from integrated level 1 trauma center in India. J Neurosci Rural Practice. 2016;7(04):515-525. Available from: https://dx.doi.org/10.4103/0976-3147.188637. doi:10.4103/0976-3147.188637.

2. Jones KW. Thoracic Trauma. Surg Clin North Am. 1980;60(4):957-981. Available from: https://dx.doi. org/10.1016/s0039-6109(16)42194-8. doi:10.1016/s00396109(16)42194-8.

3. Simon B, Ebert J, Bokhari F. Management of pulmonary contusion and flail chest: an Eastern Association for the Surgery of Trauma practice management guideline. J Trauma Acute Care Surg. 2012;73:351-61.

4. Molnar TF. Thoracic Trauma: Which Chest Tube When and Where? Thorac Surg Clin. 2017;27:13-23.

5. Marya S, Singla SL. Management of chest injuries by a general surgeon. Ind J Surg. 1987;49:235-243.

6. Mandal AK, Montano J, Thadepalli H. Prophylactic Antibiotics and No Antibiotics Compared in Penetrating Chest Trauma. J Trauma . 1985;25(7):639-643. Available from: https://dx.doi.org/10.1097/00005373-19850700000011. doi:10.1097/00005373-198507000-00011.

7. Brunner RG. The role of antibiotic therapy in the prevention of empyema in patients with an isolated chest injury: A prospective study. J Trauma. 1990;30:1148-53.

8. Mohta M, Kumar P, Mohta A, Bhardwaj R, Tyagi A, Sethi AK. Experiences with chest trauma: Where do we stand today. Indian J Crit Care Med. 2006;10(1):25-28. Available from: https://dx.doi.org/10.4103/0972-5229.24686. doi:10.4103/0972-5229.24686.

9. Massaga F, Mchembe. The pattern and management of chest trauma at Muhimbili national Hospital, Dar es Sallaam. East Central Afr J Surg. 2010;15(1):124-129.

10. Lema MK, Chalya PL, Mabula JB, Mahalu W. Pattern and outcome of chest injuries at Bugando Medical
Centre in Northwestern Tanzania. J Cardiothoracic Surg. 2011;6(1). Available from: https://dx.doi.org/10.1186/17498090-6-7. doi:10.1186/1749-8090-6-7.

11. Veysi VT, Nikolaou VS, Paliobeis C, Efstathopoulos N, Giannoudis PV. Prevalence of chest trauma, associated injuries and mortality: a level I trauma centre experience. Int Orthop. 2009;33(5):1425-1433. Available from: https://dx.doi.org/10. 1007/s00264-009-0746-9. doi:10.1007/s00264-009-0746-9.

12. Al-Koudmani I, Darwish B, Al-Kateb K, Taifour Y. Chest trauma experience over eleven-year period at al-mouassat university teaching hospital-Damascus: a retrospective review of 888 cases. J Cardiothoracic Surg. 2012;7(1):35-35. Available from: https://dx.doi.org/10.1186/1749-8090-7-35. doi:10.1186/1749-8090-7-35.

13. Kiev J, Kerstein MD. Role of three hour roentgenogram of the chest in penetrating and nonpenetrating injuries of the chest. Surg Gynecol Obstet. 1992;175:249-53.

14. LoCurto JJ, Tischler CD, Swan KG, Rocko JM, Blackwood JM, Griffin CC, et al. Tube Thoracostomy and Trauma???Antibiotics or Not? J Trauma. 1986;26(12):10671072. Available from: https://dx.doi.org/10.1097/00005373198612000-00001. doi:10.1097/00005373-198612000-00001.

15. Drummond DS, Craig RH. Traumatic haemothorax: complications and management. Am Surg. 1967;33:403-411.

16. Dalal S, Nityasha, Vashisht M, Dahiya R. Prevalence of chest trauma at an apex institute of North India; A retrospective study. Internet J Surg. 2008;18(1):84-89.

Copyright: (C) the author(s), 2020. It is an open-access article distributed under the terms of the Creative Commons Attribution License (CC BY 4.0), which permits authors to retain ownership of the copyright for their content, and allow anyone to download, reuse, reprint, modify, distribute and/or copy the content as long as the original authors and source are cited.

How to cite this article: Tolia J, Bhatt A. Prevalence of Chest Trauma at Tertiary Care Institute: A Cross Sectional Study. Acad. J Surg. 2020;3(1):48-51.

DOI: dx.doi.org/10.47008/ajs/2020.3.1.10

Source of Support: Nil, Conflict of Interest: None declared. 